\title{
Research Development of the Traditional and Flexible Shed-holes
}

\author{
Yunfei Luo ${ }^{1,3}$, Jiao Jiang ${ }^{2}$, Jianrong Yang ${ }^{1,2}$, Yitang Zhou ${ }^{2}$
}

(1. State Key Laboratory Breeding Base of Mountain Bridge and Tunnel Engineering, Chongqing 400074, China; 2. Kunming University of Science and Technology, Kunming, 650500, China; 3. Kunming Survey, Design and Research Institute Co. Ltd. Of CREEC, Kunming, 65020, China)

Keywords: shed-hole; randomness; impact force; flexible protection net Abstract:Rock-fall impact is the main threat to the roads and bridges. The research background, methodology and literature review are introduced respectively on rock-fall impact to traditional reinforced concrete shed-hole and flexible steel shed-hole. The impact force transmission mechanism is brought into focus. It combines with the advantages and disadvantages. And the development trends in the future is discussed.

\section{Introduction}

Rock-fall is one of the major natural disasters in the mountainous area of China. It has become an important factor restricting the development of the western and traffic construction. In order to prevent the rock-fall, scholars have established a number of active protective measures, such as warning device, removal of dangerous rocks, supporting reinforcement, anchorage and spray anchor seal. At the same time, some passive protection measures were also set up, such as barrier, protection and passing round ${ }^{[1]}$.

\section{The Research Status of Motion Characteristics of Rock-fall}

According to the model tests and numerical simulation, Ya Nan ${ }^{[2]}$ studied the motion characteristics of rock-fall. Based on field test, Hu Houtian ${ }^{[3]}$ analyzed the influence of rock-fall factors including its size, shape, quality and slope conditions. Tang Hongmei ${ }^{[4]}$ deduced the different start-up mode under the rock-fall trajectory equation. Based on the orthogonal experimental factors, Huang Runqiu ${ }^{[5]}$ studied the movement characteristics and influence factors of rock-fall. But most numerical simulation and mathematical models were built on the ideal model. Some scholars used average acceleration and movement time to characterize the rock-fall movement ${ }^{[6]}$.

\section{Traditional Shed-hole}

\section{Basic Structure and Research Status}

Typical shed-hole structure is generally made up of two parts: the reinforced concrete frame and cushion material with a certain thickness on the top of the frame. Cushion material can usually be of sand gravel or clay ${ }^{[1]}$. How to evaluate the impact of rock-fall pressure has become the key of shed-hole design ${ }^{[7-8]}$. The domestic basic research on rock-fall hazards is relatively rare. Technical personnel have no criterion in rock-fall protection design. For the traditional reinforced concrete shed-hole, the following three aspects of research are being mainly concentrated:

Structure local performance

When a collision occurs, because of the rigidity, it will produce a great impact force which will affect the structural safety. To reduce the impact force, the scholars change some local structures. For example, He Siming ${ }^{[1,9]}$ adds an energy absorber in the shed to increase the flexibility of the system structure. 
Overall performance

In order to determine the overall protection performance of the structure, measuring instrument is used to monitor the changes of the main force of the structure.

Numerical simulation of the overall performance

In view of the high cost of the model test, the limitation of measuring instruments and technology, the data obtained is very limited. So some scholars carry on the numerical simulation research to the shed-hole structures.

The Calculation of Rock-fall Impact Force

The impact force is one of the main loads in the design. In the specification, China does not explicitly give the algorithm of rock-fall impact force and just refers to some empirical formulas.

Roadbed standard method

Calculation formula:

$$
P=2 \gamma Z\left[2 \operatorname{tg}^{4}\left(45^{\circ}+\frac{\varphi}{2}\right)-1\right] F ; Z=V_{R} \sqrt{\frac{Q}{2 \times 10^{-3} g \gamma F}} \times \sqrt{\frac{1}{2 \operatorname{tg}^{4}\left(45^{\circ}+\frac{\varphi}{2}\right)-1}}
$$

$P$ : Impact force of falling stone $(\mathrm{N})$;

$V_{R}:$ Rock speed $(\mathrm{m} / \mathrm{s})$;

$Z:$ In the depth of the buffer layer of rock-fall (m);

$Q:$ Rock mass $(\mathrm{N})$

$g$ : Gravitational acceleration $\left(9.81 \mathrm{~m} / \mathrm{s}^{2}\right)$;

$\gamma:$ Buffer layer $(\mathrm{N} / \mathrm{m})$

$\varphi$ : Buffer layer internal friction angle $\left(^{\circ}\right)$;

$g:$ Severe rock-fall $(\mathrm{N} / \mathrm{s})$;

$F:$ The cross-sectional area of the equivalent sphere of rock-fall $\left(\mathrm{m}^{2}\right)$.

This is actually the average impact of a process of rock-fall impact force, rather than the maximum impact force. Through the rock-fall tests, Ye Siqiao ${ }^{[10]}$ has demonstrated that calculation results of this method was too small.

Tunnel Manual Method

Calculation formula:

$$
P=\frac{Q V_{0}}{g t}, t=\frac{2 h}{c}, c=\sqrt{\frac{1-v}{(1+v)(1-2 v)} \frac{E}{\rho} \times 10^{-3}}
$$

$P$ : Impact force of falling stone $(\mathrm{N})$;

$v$ : Poisson's ratio of soil;

$Q:$ Rock mass $(\mathrm{N})$;

$E$ : elastic modulus of soil $(\mathrm{Pa})$;

$g:$ Gravitational acceleration $\left(9.81 \mathrm{~m} / \mathrm{s}^{2}\right)$;

$\rho:$ density of soil $\left(\mathrm{kg} / \mathrm{m}^{3}\right)$;

$V_{0}:$ Rock speed $(\mathrm{m} / \mathrm{s})$

$t:$ Impact duration (s);

$c$ : Compression wave velocity in the buffer layer $(\mathrm{m} / \mathrm{s})$;

$h:$ Buffer layer thickness (m).

This method calculates the smallest results for two reasons: The impact of the law through the impulse theorem is the average impact force. In Engineering, the maximum impact force is needed for the structural design; Impact duration is too long, which leads to a small average impact force. 
Yang Qixin Method

Calculation formula:

$$
P=\xi m a_{\text {max }}, a=\frac{\sqrt{2 g H}}{t}, t=\frac{1}{100}\left[0.097 m g+2.21 h+\frac{0.045}{H}+1.2\right]
$$

$P$ : Impact force of falling stone $(\mathrm{N})$;

$H$ : Falling Rocks free fall height (m);

$a_{\max }$ : Maximum acceleration $\left(\mathrm{m} / \mathrm{s}^{2}\right)$;

$g$ : Gravitational acceleration $\left(9.81 \mathrm{~m} / \mathrm{s}^{2}\right)$;

$t:$ Impact duration (s); $m$ : Rock quality (kg);

$h$ : Buffer layer thickness (m);

$\xi$ : The coefficient which is about buffer layer's density. Experimental conditions take 1.

Using this method, we get average impact force. It reflect the quality of rock-fall, influence of buffer layer thickness and impact velocity. But the result is still small because of the theoretical basis ${ }^{[11]}$.

Method of Japanese Road

Calculation formula:

$$
P=2.108 \times 10^{-1} m^{\frac{2}{3}} \lambda^{\frac{2}{5}} H^{\frac{3}{5}}
$$

$P$ : Impact force of falling stone $(\mathrm{N})$;

$m$; Rock quality (kg);

$\lambda:$ Lame constant;

$H$ : Falling Rocks free fall height (m).

Swiss Method

Calculation formula:

$$
P=1.765 M_{E}^{\frac{2}{5}} R^{\frac{1}{5}}[Q H]^{\frac{3}{5}}
$$

$P$ : Impact force of falling stone $(\mathrm{N})$;

$H$ : Falling Rocks free fall height (m);

$M_{E}$ : Buffered soil deformation modulus $(\mathrm{Pa})$;

$R$ : The equivalent radius of rock-fall (m).

$Q:$ Rock mass $(\mathrm{N})$;

Ye Siqiao and Tang Hongmei ${ }^{[10]}$ found Japan and Swiss formula calculated results were close, and they were the biggest impact force. Therefore, the calculated results are more close to the real value. But the formulas need too many empirical constants.

\section{Flexible Shed-hole}

\section{Research Status}

Many scholars have carried out a lot of research work. For example, between the roof and beam, Delhomme ${ }^{[12]}$ placed the metal dampers. Wang Dongpo and He Siming ${ }^{[13]}$ applied the EPS materials to energy dissipation engineering. Compared with the traditional shed-hole, the flexible shed-hole consumes more energy, and construction and maintenance costs are relatively low. What's more, it can better protect the environment. Therefore, it is of great superiority in the aspects of applicability, safety, economy and environmental protection, and it is worthy of promotion and application ${ }^{[14]}$. Up to now, scholars mainly have researched the design of flexible shed-hole. They have discussed the characteristics of deformation and failure. This shows the rationality of the structure system and deformation and stress to content the relevant specifications ${ }^{[15]}$. For traditional reinforced concrete shed-hole, scholars have done a lot of work. But for flexible steel shed-hole, their research and design are not enough, and a large number of structural calculations are also without validation object. In the design and operation, a lot of content are staying in the primary stage. 
Mechanism of Transmission

The deformation process can be divided into three stages:

(1) When rock-fall contact with flexible shed-hole, metal net is stretched by the load.

(2) The remaining load is passed to the support rope. At this point, the steel column is also affected by the impact, but its deformation is relatively small.

(3) With the further increase of the impact, the steel column have to hem to make the system obtain a new energy dissipation capacity. Finally, the load is transmitted to the bolt bedrock and the formation of the system ${ }^{[14]}$.

Future Development

The new type of flexible steel shed-hole is lighter than the traditional steel reinforced concrete shed-hole in weight. It does not require a larger basis, and the construction and maintenance costs are lower. What's more, in the construction aspect, once the sizes are determined, they can be prefabricated. If so, this can significantly reduce the construction time.

But research and design are not enough. Metal shield, as the main energy consuming component, in the overall structure of the performance test and design methods are still lack of research. So metal protective net force test under rock falling has an important research value. And it can provide basic data and preparation for the design theory of metal shield. Research and design of the metal shield were highly simplified. Performance of many components could not fully play. So it caught partial material waste. Therefore, optimization design of the system components is also to be solved urgently. New type of flexible steel shed-hole has a greater advantage in the applicability, safety, economy and environmental protection. In the future, the new type of flexible shed-hole will occupy main role.

\section{Conclusion}

(1) In the specification, our country does not explicitly give the algorithm of rock-fall impact force and just refers to some empirical formulas. So the calculation of rock-fall impact force is one of the problems to be solved.

(2) For flexible steel shed-hole, its research and design are not enough, and a large number of structural calculations are also without validation object. In the design and operation, a lot of content staying in the primary stage.

(3) Compared with the traditional reinforced concrete shed-hole, flexible steel shed-hole has a greater advantage in the applicability, safety, economy and environmental protection. In the future, the new type of flexible shed-hole will occupy the main role.

\section{Acknowledgement}

Supported by the State Key Laboratory Breeding Base of Mountain Bridge and Tunnel Engineering Funding (Chongqing Jiaotong University, Grant No. CQSLBF-Y13-9). 


\section{References}

[1] HE Si-ming, SHEN Jun, WU Yong. Rock Shed Dynamic Response to Impact of Rock-fall [J]. Rock and Soil Mechanics, 2011, 32(3): 781-787.

[2] YA Nan, WANG Lan-sheng, ZHAO Qi-hua, XU Jin. Simulation Study of Rock-fall Kinematics [J]. Journal of Geological Hazards and Environment Preservation, 1996, 7(2): 25-32.

[3] HU Hou-tian. Research on the Collapse and Falling Stone [J]. JOURNAL OF RAILWAY ENGINEERING SOCIETY, 2005, 12(Supplement): 387-390.

[4] TANG Hong-mei, YI Peng-ying. Research on Dangerous Rock Movement Route [J]. Journal of Chongqing Jianzhu University, 2003, 25(1): 17-23.

[5] HUANG Run-qiu, LIU Wei-hua, ZHOU Jiang-ping, PEI Xiang-jun. Rolling Tests on Movement Characteristics of Rock Blocks [J]. Chinese Journal of Geotechnical Engineering, 2007, 29(9): 1296-1302.

[6] XIANG Xin. Research on Motion Characteristics and Impact Force of Rock-fall [D]. Wuhan: China University of Geosciences, 2010: 4, 35-36.

[7] V. Brizmer, Y. Kligerman, I. Etsion. The Effect of Contact Conditions and Material Properties on the Elasticity Terminus of A Spherical Contact [J]. International Journal of Solids and Structures, 2006, 43(18-19):5736-5746.

[8] B. Pichler, Ch. Hellmich, H.A. Mang. Impact of Rocks onto Gravel Design and Evaluation of Experiments [J]. International Journal of Impact Engineering, 2005, 31: 560-578.

[9] HE Si-ming, WU Yong. Research on Cushioning Mechanism of New-typed Energy Dissipative Rock Shed [J]. Chinese Journal of Rock Mechanics and Engineering, 2010, 29(5): 926-932.

[10] YE Si-qiao, CHEN Hong-kai, TANG Hong-mei. Comparative Research on Impact Force Calculation Methods for Rock-falls [J]. HYDROGEOLOGY \& ENGNEERING GEOLOGY, 2010, 37(2): 59-63.

[11] GUO Shao-ping, WANG Quan-cai, WU Qing, ZHANG Qun-li. An Improved Impact Force Calculation Method for Rock-fall [J]. MOUNTAIN RESEARCH, 2014, 32(3): 346-347.

[12] F. Delhomme, M. Mommessin, J. P. Mougin, P. Perrotin. Behavior of A Structurally Dissipating Rock-shed: Experimental Analysis and Study of Punching Effects [J].Rock and Soil Mechanics, 2009(3): 623-627.

[13] Wang Dong-po, HE Si-ming, LI Xin-po, XIANG Bo. Study on the Dissipating Effects of Shed with EPS Cushion under Impact Load [J].JOURNAL OF SICHUAN UNIVERSITY (ENGINEERING SCIENCE EDITION), 2012, 44(6): 102-107. 
[14] LIU Cheng-qing, CHEN Lin-ya, CHEN Chi, WEI Tao. Experimental Study on the Passive Flexible Protection under the Rock-fall Impact [J]. The Chinese Journal of Geological Hazard and Control, 2014, 25 (4): 38-39, 41-42.

[15] REN Xin. The Application and Research of Flexible Protection Technology in the Rock Slope Collapse and Rock-fall Hazard Management Project [D]. China University of Geosciences (Beijing), 2011: 3-8. 